\title{
A BIBLIOGRAPHY OF SCIENCE TEACHING.
}

\author{
B.Y W. L. EIKENBERRY.
}

A conmittee of the American Federation of Teachers of the Mathematical and Natural Sciences has been at work some time upon the preparation of a select list of references upon the teaching of the sciences. Their work has been issued by the Government Printing Office as Bulletin 1, 1911, C. S. Bureau of Education, under the title, Bibliography of Science Teaching.

There are some three hundred and seventy citations classified in Biology, Chemistry, Geography, Mathematics, Nature Study, and Physics. The limits as to number of references compelled very close selection and elimination. The titles that remain represent "really serious contributions to the feld." The bulletin should have a large circulation. It is fortunate that it is issued in a form that makes it so easily and so generally apailable.

The thanks of seience teachers everywhere are due to the members of this committee who have labored so effectively in this matter.

\section{CEMENT EXPANSION STUDIED BY CHEMICAL ENGINEERS.}

Cement sidewalks grow. For that reason one must leave expansion joints at short intervals to prevent the walk from growing humpbacked. Furthermore, cement sidewalks shed their top coat often as a snake sloughs its skin. Both these phenomena are explained, says Professor A. H. White of Chemical Engineering Department of the University of Michigan, by the curious expansion of cement when moistened. The unique feature which causes the trouble is that cement once expanded by water never sbrinks quite to its former dimensions upon drying, and therefore thére is a constant tendency for it to increase in size. In this way a long sidewalk might grow a foot or more in ten years, though the rate of growth seems, from long time tests, to decrease with time.

The peeling of the top coat, so often noticed, is due to the fact that this coat contains almost all cement and little sand. Pure cement expands more than cement and sand, and therefore the top coat outgrows the sidewalk which it covers, and peels off.

\section{ANTARCTIC COAL.}

The discovery of several seams of coal, a few inches to $7 \mathrm{ft}$. in thickness, in the sedimentary strata of a mountain in the Antarctic region, and of fossil remains of conifer trees by Lieutenant Shackleton's recent expedition, is a very remarkable one, and is analagous to similar discoveries of coal accompanied by fossil imprints of semi-tropical or temperate-zone foliage within the northern Arctic Circle, and in such high altitudes as those of Spitzbergen and northern Alaska, both the coal and the fossil foliage go to show that a very different climate than now, once prevailed in those regions-a climate comparable to that of Europe and the middle and southern states of North America, or even warmer. To account for such warm conditions is as difficult as to account for the present great ice-cap at the poles, and that of the glacial epoch, whether we assume a geological or an astronomical cause of these strange phenomena, such as local subsidence and elevation of land at the poles, or that the axes of the earth have changed places with regard to their position and distance from the sun and its heat. 